\title{
The Artistic Approach of Mandanipour on Farsi Language Applied in Shargh-e Banafshe Book
}

\author{
Somaye Sadeghian ${ }^{1} \&$ Mohsen Mohammadi Fesharaki ${ }^{1}$ \\ ${ }^{1}$ Faculty Literature \& Humanities, University of Isfahan, Isfahan, Iran \\ Correspondence: Somaye Sadeghian, Faculty Literature \& Humanities, University of Isfahan, Isfahan, Iran. Tel: \\ 98-913-892-9239. E-mail: dr.sadeghian@hotmail.com
}

\author{
Received: August 17, 2012 Accepted: September 27, 2012 Online Published: December 28, 2012 \\ doi:10.5539/ach.v5n1p60 \\ URL: http://dx.doi.org/10.5539/ach.v5n1p60
}

\begin{abstract}
The formalist linguists are of the opinion that the literary language is formed by polishing and foregrounding the practiced slang. Many of this literary tricks used in foregrounding are categorized; but there exist some literary tricks that have not been dealt with and are not named or addressed in the available categories. The attempt is made in this study to find an answer to the questions that why has Mandanipour in his masterpiece, "Shargh-e Banafshe" achieved a superior language that is outstanding among his colleagues of the same era and has become a model in advanced language for the writers to come based on adopting defamiliarization theory in the Leech foregrounding format? Assessing the language of this unique work indicates that in addition to introducing an innovation in the usual styles in contemporary writing and the themes he has allowed assimilation and metaphor and other obsolete styles in his language; and yet has used special literary tricks that have never been tried or tested before. This approach has pat language in story writing to a high position.
\end{abstract}

Keywords: Shahryar Madanipour, language, defamiliarization, foregrounding, formal commenting

\section{Introduction}

The story write, Shahryar Mandanipour is among the third generation of contemporary writers of Iran. His masterpiece the "Shargh-e Banafshe" and other famous works like: "The Noon Moon", "The mummy and Honey", "The Shadows of the Cave" and a book about story writing techniques named "The Sharzad's Ghosts" have made him the pioneer of the writers who has his own "genre" in Iran. His stories in different aspects of story writing are created in a very artistic manner. One of these aspects which prove this claim is the language used in his masterpiece noted above. In his work the element of language is the dominating factor and by flourishing the literary spectrum of this element he has made his work everlasting.

Here, with a linguistic perspective based on the theories of some formalist linguists, like leech and Shklovskij the language of "Shargh-e Banafshe" is evaluated in order to determine the writers uniqueness.

For this purpose, first his defamiliarizations and his innovations with respect to the literary language are discussed in Leach framework; next the non-categorized foregrounding of the literary works will be focused on. The findings may indicate whether his work would fit in the categories of Leech's pattern or is not categorizable at all and yet might be a combination of both the categorized and non-categorized species.

The defamiliarizations concept in Iranian literature has been applied to the poetry at the most. In the story writing realm, Mandanipour's "The Thousand and One Years" has been subject to linguistic analysis by Zari Naimi but not his masterpiece.

\section{The Literature Language in A Linguistic Perspective}

The Russian formalism evaluation was the beginning of the revolution where the literary works would be subject to regulated frameworks according to scientific justifications. The linguists defined the literary language based on its similarity with the standard day-to-day language and for distinguishing these two the Automatisation and Foregrounding expressions were applied. For example, Mukarovsky (1932) is of the opinion that the standard language is a background in poetry and this language and the literary function of it is formed by conscious distortion and the aesthetic recognition of components of the slang. In his view the literary language is not for communication, but a reference to its own. The same conception is trough with Jakobson, who is of the opinion that language is literary when the intention of the message is reflected on the message itself and not creating a 
connection or expression with theme (Fowler, 1996). Martinet (1960) considers this linguistic contribution as creating aesthetic.

Foregrounding is the conscious default of slangs in the standard and day-to-day language in a sense that the presentation pattern is attractive while in common_and not automatized. It could be claimed that among the linguists Leech has presented the most comprehensive pattern for language foregrounding which is of two types: first, introduction of some deflection to the prevailing regulations on language automatization that would end up in Deviation; second, addition of some regulations to the prevailing regulations on language automatistion that would end up in Extra regularity.

Leech divides the deviation into eight types:

Lexical, Grammatical, Phonological, Graphological, Semantic, Dialectical, Register and historical period deviations.

He considers the extra regularity addition as a result of phonological balance and harmony at the phoneme, term, sentence and speech levels.

According to Leech the poetic options are of two: simple and innovative. In the first option the traditional aspect is applied but in the second the language boundaries are expanded and seek new horizons and realms (Leech, 1969). According to this view point, language becomes attractive when it is fresh and unknown to the audience. Therefore, foregrounding like all other literary tricks in the realm of art that has a strong bound with defamiliarization. In his first address to defamiliarization theory in literature and art, Shklovskij said:

"The purpose of art is to impart the sensation of things as they are perceived and not as they are known. The technique of art is to make objects unfamiliar to make forms difficult to increase the difficulty and length of perception, because the process of perception is an aesthetic end in itself and must be prolonged. Art is a way for experiencing the artfulness of an object, the object is not important" (Shklovskij, 1998).

The horizon is open to the innovative artist to allow him/her to test the literary tricks for making the work more attractive in a manner that no other has done before and if done, have not been foregrounded and are nameless and not even categorized, to say more, they are neither lexical deviation nor extra regulatory; therefore, innovative diversion that is defamiliarization from standard language on one hand and defamiliarization from the current literary language on the other would make a literary work immortal in the writing realm.

\section{Foregrounding Concept in "Shargh-e Banafshe"}

Mandanipour emphasizes on the essence of language and considers it as the distinguishing aspect between contemporary story writing and the traditional style. He claims that "the traditional story writing applies the language as a tool, a tool to announce an incident; while the contemporary writing is far from this sense. Here language is the objective. Hence, narrating the incident is no more the essence, but its conversion to language, converting the incident into words is the incident of our century" (Alikhani, 2001).

This same attitude is reflected and materialized in his masterpiece when he has applied all the elements of his famous claim above.

Unlike many of the contemporary story writers, he usually applies lexical deviation in an exuberant manner in addition to introducing innovative aspects some of which are defined in the literary framework and some not. His tendency towards different semantic devotion has made his prose poetic.

\section{The Semantic Deviation}

The collection of linguistic units is developed through the semantic components that are subject to specific regulations; but, if in the theme the semantic rules' combinations are ignored with no distortion in the semantic contribution a reduction in semantic axiom has taken place Short (1996) claims.

"Let us define semantic deviation as meaning relations which are logically inconsistent or paradoxical in some way" (Short, 1996).

This type of deviation is the most practical method used in foregrounding the language in "Shargh-e Banafshe". Mandanipour, on one hand uses the semantic deviation literary tricks that are used less in today's writings-amphibology, reliable linguistic analysis, contrariety and exaggeration, adjective replacement and innovative allusions and metonymies- and on the other, renovates the commonly used current literary tricks of the contemporary writing which are the proportional metaphors and assimilations. His attribution to this component in symbolic stories in parallel to the use of common forms of through semantic deviation does not make his works fit in any category established so far or is beyond the title that might be given. Here, his 
innovations in the Simile, Metaphor and Intertexuality aspects are discussed with respect to semantic deviation concept.

\subsection{Simile}

Mandanipour reveals his attempt in exaltation of language in the mind of the reader, since similes contribute less to the progress of the theme and more to the more the verbum. In his book, some of stories, in certain parts, brake down due to the subjective dialogue of the love to the beloved regarding her face, hair, body, height and other features.

These deviations are is prose just like poetic and mystical codes installed in different layers of the story structure; something rarely seen in today's writings. Mandanipour adopts this method for the purpose of wakening the authentic fresh sense of the good Persian language in the old beloved; a sense that was almost going to fade away.

"I say: your hair, the warm tent of a hunting night; the eyes, two bright stars for the hunter set next to the fire. I say so: your footstep, deer's walk, softness of your hands, swan feather, you aroma, musk and amber, your affection a mountain of pearl" (Mandanipour, 2005).

This fact has made him to incline towards the similes like that of the submerged simile through dilettante. Some odd types of simile is observed in his writings besides the above mentioned points: "suddenly he is there; like a non-prophesied fear, he is there"

\subsection{Metaphor}

There exists a type of a metaphor in Farsi language where the concept of "similar to" is implicit and the similar is expressed true the attachments of the "similar to".

The most common way to distinguish this type of metaphor is personification where "similar to" is absent and "simile" is not animate. The other type where the "similar to" is not animate is rarely used. Mandanipour uses the absolutely hidden metaphor in non- determinant just the same way as used in the determinant sense and this fact makes his metaphors more artistic: The sacrifice had a look at him. A morn full lamentation blew on him (Mandanipour, 2005).

Here the morn full weep resemble the wind and the feature of "similar to", which is the wind blow is mentioned for the "simile". He sometimes uses the same metaphoric style in a combined explanatory form, that is, the attachments of "similar to" act as adjective for the "simile".

\subsection{Intertexuality}

According to Makaryk (1993), Intertextuality is of the notion that text is an independent, closed circuit non-self-sufficient system while having a two-fold connection neck-to-neck with other texts. Therefore, any textual connection with other texts is named Intertextuality, whether this connection lead to defamiliarization of the language or just be a follower of the styles of others within material and far from aesthetic values. In "Shargh-e Banafshe" the intertextuality has become the most important factor in the literacy of the language in a quotation, allusion and above them a high artistic frequency. The "Shargh-e Banafshe" series of stories begins with a story with the same name that the book has. In this story, quotation in full or in part (Kazzazi, 2006) is one of the connecting modems bridging the narrator with his greatness Hafez, in a noumentalist sense. Mandanipour has borrowed some practical words, terms, combinations, and expressions from the collections/Divans of Hafez and applies, blends and fits them with his own linguistic symbols in a manner that, in most cases, the borrowed materials are promoted beyond creating literary beauty, that is, at the top of conciseness, it contributes to the semantic aspect of the writing significantly. Here the semantic allusion should be obtained from the text where these elements are extracted from. In fact the function of this type of quotation, where the illusion and conciseness are combined is beyond just a quotation while in the rhetoric no name is found for it.

Allusion points to the context of a story, an exemplary idea or a saying from others (Kazzazi, 2006). In "Shargh-e Banafshe" story, most type of allusions are evident, while in some cases the Intertextuality seems deeper than the mere allusion. In conciseness allusion is a temporal indication to an issue in another text that only adds to the beauty of the text and its presence in the verbum, here structure is not necessary. Mandanipour, in his masterpiece has stepped beyond these limits and fit the theme borrowed from others in the texture of his own wording in a manner that it becomes an inseparable part of the whole with no disturbance in the flow. Under these circumstances the chosen terms and, linguistic symbols become more highlighted and expresses more than usual. 
In our subject story, in addition to the connection of the content of the letters exchanged between lover and beloved, the narration of narrator, sometimes a connection is formed with the previous themes.

The narrator, for the first time reveals the romantic codes in the Divan of Hafez; therefore, the language of the narrator is influenced by both the Language and the theme of the Divan in an indirect manner.

Likewise the letter exchanged between "Zabih" and "Arghavan" are channeled through letter marks writhen on the books of the library. This in itself, is a reason for the subject of the letter to be affected by the name of the book that is coded where usually both have subjective unity. The "Blind Owl" is the first book which the lover admits to his beloved, and this same book, the names of which is a symbolic style initiates the turbulence in the life of both the young.

A simile created by Mandanipour is inspired by the content of book named "The small prince", where he concludes that:"Your windows is the small planet where only one red flower is flourished, among all the stars and it's not clear each one (Mandanipour, 2005).

In the letter written in "Layli and Majnoon" book, the names of the lover and the beloved become evident for the narrator. The writer, before ending to story leads the reader to the faith of these two, a faith of "Layli and Majnoon".

Intertextuality is evident in "Aylar" story as well in a different form. If we accept that the movies and theater are visual themes that sometimes interact with the written themes, then Mandanipour has expanded the Intertextuality's realm. In "Aylar" the story theme is on twined with the theme outside itself, that is, the movie that the lover sees in the cinema. Taleba expresses his fear from love to his hardly found and priceless beloved like Aylar in an indirect manner by explaining the thriller movie while both are watching:

"It is a sand storm, Aylar and the pyramid behind the fog of dust is the shade that frightens love" (Mandanipour, 2005).

In another section, this fear is revealed in a dark and fearsome space in the movie. Here four men dressed in black around a woman with eyes of honey color, a personification of the four detectives following Aylar in the story.

In addition to this, the theme of a story that Sadegh Hedayat reads for a girl in a café is predicting the occurrence of a vicious love event in the main theme the end of which is nothing but phonetic and a secret life.

\subsection{Some Unknown Aspects of Semantic Deviation}

After ending the discussion on semantic deviation we deal with some of the irregular collections, combinations and the unfamiliar bland of symbols in Shargh-e Banafshe, innovated by its writer, applying his own potential facilitation, things that do not exist in standard language. Expressions and combinations innovated in this manner make the writer's language unique in comparison with his colleagues and register a new style specific of him. Here are two samples of such literary tricks:

"Her eyes, similar to the eyes that open their curtain furtively, just enough to allow the breeze to blow through for two violets are looking at the exterior of an interior".(Mandanipour, 2005).

In the above statement the incomparable adverb, just enough to allow the breeze to blow through is to express the passage of sight, something that does not fit in any standard image while in a sense it is raised from the power of imagination; therefore, makes the language poetic.

"After one minute their sight converted into one eye, Arghavan stood up."

Conversion of sight into one eye is an interpretation for expressing the intertwining the sight in one another; Mandanipour is the first writer to use such interpretation.

\section{Grammatical Deviation}

This deviation is concerned with the displacement of sentence elements without observance of the linguistic elements. Ellipsis or applying improper linguistic elements, lack of agreement in the constituent elements of the sentence and verb usage with explicit subject are some of the issues regarding this type of diversion (Leech, 1996).

In some stories of "Shargh-e Banafshe" book, where the selected language is formal and standard, and yet all deviations are protected in the sentences, refusal of the grammatical rules in the language are non-customary and this leads to the freshness in the language.

\section{Deviation of Historical Period}

This kind of diversion has to do with the time concept of standard application of language; the forms that were common, but are obsolete now (Leech, 1996). 
The atmosphere of the "Shargh-e Banafshe" story which is a mixture of the narrator's era with that of the Hafez's, in addition to his deep emotional connection with the Divan of Hafez has made him use the common terms of the very old past once in a while. The frequency of this deviation's application in this story has given an advantage to it when compared with other contemporary similar writings.

\section{Deviation of Register}

When by applying the style varieties, a deviation from the main layer, which is the written language standard a style of deviation is materialized (Leech, 1969). This type of deviation in Persian stories usually appears when the language is broken and becomes common in the story characters' dialogue. In our subject book, here and there, we see the same phenomenon as being different from what other contemporary writers have applied in their writings. This is in a sense that no quotations are used.

In some of the stories in this book, there are different types of narrators with different speaking styles. Then the possibility of intonation and style change is there. For example, in one of the stories, the main narrator's language has tendency towards the old schools of language. As the other narrators begin to speak, suddenly the language changes form that is the main narrator's era's standards. This literary trick is rarely applied in the contemporary stories; therefore, it makes the defamiliarization in our subject book two fold.

\section{Lexical Deviation}

"Neologism or invention of new words is one of the more obvious ways in which a poet may exceed the normal resources of the language" (leech, 1996).

The structure of the terms in the story language that is formed due to a change in the construction of the available terms and their combinations in standard language is a part of the defamiliarization, a rare occurrence through deviation that highlights the work and establishes a new school of writing pattern that gives freshness to the language. This is evident in Mandanipour's outstanding work, the subject of this study, where he innovates terms that all follow a unified structure. These terms mostly relate to the phonetics aspects of language and all have equivalents in the language, but Mandanipour introduces changes in the phonetic structure of these terms. The rest are formed in the language by changes made in the stipulations.

\section{Graphological Deviation}

Here the writer applies a literary trick in his writing where no change is felt in the term pronunciation but a secondary conception next to the conception of the main term (Leech, 1996). This type of deviation is very rare found in literary language especially in story writing, but its presence in our Shargh-e Banafshe is one of the distinguishing elements in language style innovation for the author. In the following examples the continuation of the vowels $\mathrm{A}$ and $\mathrm{O}$ associate with the sounds in the audience mind that are necessary for the images of the following sentences:

"Due to the pain he grinned his teeth and the sound of their cracking cried in his ears: He cried "Ay...Laaar" (Mandanipour, 2005).

The echo of vowel A in the term Aylar is associated with the cry that is formed in the air.

"Yes, put an end to it"; "Are ....tamoo....oo.....mkon...id" (Mandanipour, 2005).

The repetition of the vowel $\mathrm{O}$ in the term "tamoom" represents the concept of burning; since, usually the noise that human makes due to a burn is represented with $\mathrm{O}$.

\section{A Bridge between Form and Romanticism, the Balance}

Balance in writing, according to Leech is incremental to the regulations in many types. In general, when the terms, the sentences and the grammatical array is intact, that is these elements correspond to one another, there is phonetic wording (Leech, 1996). In story writing balance and musical harmony are rarely found; but Mandanipour in his work, has emphasized on this type of foregrounding that makes his works distinguished. The point to be considered here is that in his stories in addition to the formed promotion of language level, a neck to neck connection is observed with the theme of love that develops a meaningful musical coordination among the world setting that shades more light on the space where love evolve in the story. This makes us think of balance not only as increment in writing but a means of artistic creativity, a point where the limits of increment and subtraction of rules cross.

\section{Adverbial Clause Integrated in the Sentence}

One of the linguistic features of some stories in "Shargh-e Banafshe" is using a combination of adverbial clause and adverb in a prolonged manner in the inner parts of the sentence while they could have been used separately 
in the same sentence. It could be said that this is another innovation by Mandanipour. In a sense the adverbial clause is integrated in the sentence.

\section{Evaluation and Analysis}

Most of the stories in our subject matter contain the theme of love and this theme ask for appropriate poetic language; they are some of very rarely written stories where a full possibility of an innovative language is applied. Mandanipour has gone where other writers of his era had no notion or dared to go; a literary atmosphere where language has found its outmost artistic functionality. He is a writer who has fully accomplished all old and new linguistic knowledge of eastern literature and culture and is fully aware of all rules and regulation and yet diverts from all in an artistic manner. His grate literary evolution causes the hidden capacities and possibilities of the language to become evident and transparent and makes them flourishing. He extracts all the potential might of the Farsi language and paves the way for a big literary revolution.

In the contemporary stories overcoming the foregrounding styles is accomplished through semantic deviation, genre, grammatical and historical period deviations. Mandanipour has applied these styles in a vast innovative span in addition to resorting to rarely applied lexical, graphological deviations and escaping the rules. Some of his innovations do fit in defined categories and some do not. His most attractive and professional innovations is building a bridge between the theme of the story and the themes outer world, this bridge can be explicit in writing or implicit in vision, like the movies.

Register deviation applied by him, which is the manner of his connection with his story character, is another distinguishing point of his artistic presentation. All these literary tricks make it hard and difficult for the expert to find a title for his work style. Some of his literary tricks used in our selected collection are:

- Selecting and coexistence of symbols in a strangely defined chain addressed to semantic deviation that cannot be tagged in literary aesthetic sciences

- Creating a state of equilibrium that integrates musical sense in language is accompanied with semantics

- Applying adverbial clauses, something used in standard language in sentence form with no other application in Farsi language

\section{Conclusion}

Mandanipour with his extraordinary capabilities in utilizing the outmost possibilities and potentials of the language has presented works that are ranked at the top of the list of the best writings in Farsi language. With his innovation in Farsi literature format and the test made on his literary tricks outside the framework he has become distinguished. He has shade a new light on "story writing" in Iran and his unnamed/tagged genre is beginning to be followed by the new generation of writers.

\section{References}

Alikhani, Y. (2001). The Third Generation. Tehran, Iran: Nashr-e Markaz.

Fowler, R. (1996). linguistic criticism. New York, NY: Oxford university press.

Kazzazi, M. J. (2006). Persian Rhetoric (3). Tehran, Iran: Nashr-e Markaz.

Leech, G. N. (1969). A Linguistic Guide to English Poetry. New York, NY: Longman.

Makaryk, I. R. (1993). Encyclopedia of Contemporary Literary Theory approches, scholars, terms (Vol. 3, pp. 568). Toronto, Canada: University of Toronto Press.

Mandanipour, S. (2005). Shargh-e Banafshe. Tehran, Iran: Nashr-e Markaz.

Martinet, A. (1960). Elements De Linguistique General. Paris, France: Colin.

Mukarovsky, J. (1932). Standard Language and Poetic Language. In P. Garvin (ed.), Prague School Reader in Esthetics, Literary Structures and Style. Georgetown, USA: Georgetown Press.

Shklovskij, V. (1998). Art as Technique. Malden, USA: Blackwell Publishing Ltd.

Short, M. (1996). Exploring the Language of Poem, Plays and Prose. London and New York, England \& NY: Longman. 